\title{
OBSERVACIONES AL DICCIONARIO PANHISPÁNICO DE DUDAS (DPD) ${ }^{1}$
}

\author{
Luisa Portilla Durand \\ Universidad Nacional Mayor de San Marcos \\ http://sites.google.com/site/publicacionesvarias
}

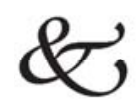

Resumen

\begin{abstract}
En octubre del 2005 se publicó el Diccionario panhispánico de dudas (DPD), texto que "se propone servir de instrumento eficaz para todas aquellas personas interesadas en mejorar su conocimiento y dominio de la lengua española» (p. xiII); sin embargo, a pesar de dicho propósito, la obra presenta serias inconsistencias y contradicciones en sus propuestas prescriptivistas.

Evidentemente, el análisis y las observaciones no se agotan en el presente artículo; pues el interés al redactarlo es compartir sólo algunas reflexiones respecto de ciertos criterios normativos que requieren ser discutidos, sobre todo por quienes estamos interesados, particularmente, por mejorar nuestro conocimiento y dominio de la lengua española.
\end{abstract}

Palabras claves: lengua española, DRAE, normativa española, DPD, panhispánico de dudas

\section{Abstract}

The Diccionario panhispánico de dudas (DPD) was published in October 2005. It is a work that "aims at serving as an efficient instrument useful to all the people interested in improving their knowledge and command of the Spanish language» (page XIII); nevertheless, in spite of that intended goal, the aforesaid work has serious inconsistencies and contradictions in its prescriptive proposals.

Certainly, all possible analysis and remarks cannot be set out in this paper, as the interest in its writing is just to share a few reflections on certain normative criteria that need to be discussed, especially by

1 El presente artículo deriva de la ponencia que expuse (en extenso) el viernes 18 de setiembre del 2009 en el IV Congreso Internacional de Lexicología y Lexicografía, en Lima (Perú).

LeTRAS 81 (116), 2010 
Luisa Portilla DuRand

those of us with a particular interest in enhancing our knowledge and command of the Spanish language.

Key words: Spanish language, DRAE, Spanish language normative, DPD, Panhispanic Doubt-Clearing.

\section{Introducción}

En octubre del 2005 se publicó el Diccionario panhispánico de dudas (DPD), texto que «se propone servir de instrumento eficaz para todas aquellas personas interesadas en mejorar su conocimiento y dominio de la lengua española» (p. xIII); sin embargo, a pesar de dicho propósito, la obra presenta serias inconsistencias y contradicciones en sus propuestas prescriptivistas.

Mi interés al redactar el presente artículo es exponer algunas observaciones al DPD, ya que dicho texto figuran ciertas propuestas bastante discutibles, no sólo por su contenido, sino, sobre todo, porque van en contra del uso léxico mayoritario, lo cual desvirtúa la naturaleza informativa y normativa de un diccionario de dudas.

En cuanto a los puntos a tratar, debo precisar que el análisis se efectuará, fundamentalmente, a partir de la revisión de las entradas (palabra o frase que es objeto de definición) y definiciones que figuran en el DPD (y, en caso de ser necesario, se citará también lo consignado en el Diccionario de la Real Academia Española [DRAE] 2001 y en versiones anteriores, así como la versión del DRAE en línea de la 23. ${ }^{a}$ edición del Diccionario), entradas y definiciones que se acompañarán de las respectivas observaciones respecto de los usos CONSIDERADOS «INNECESARIOS»; ENTRADAS O DEFINICIONES ERRÓNEAS; ENTRADAS Y DEFINICIONES EN LAS QUE PREDOMINA INJUSTIFICADAMENTE EL GÉNERO MASCULINO.

Evidentemente, el análisis y las observaciones no se agotan en el presente artículo; pues el interés al redactarlo es compartir sólo algunas reflexiones respecto de ciertos criterios normativos que requieren ser discutidos, sobre todo por quienes estamos interesados, particularmente, por mejorar nuestro conocimiento y dominio de la lengua española.

\section{Usos considerados "innecesarios" \\ hobby}

En el DPD (p. 342) se encuentra la palabra hobby de la que se dice lo siguiente: «Voz inglesa que se emplea con frecuencia en español con el sentido de 'actividad que se practica habitualmente, por mero entretenimiento, en los ratos de ocio'. Se recomienda usar en su lugar los equivalentes españoles afición o pasatiempo». 
En primer lugar, en este caso se observa desacuerdo entre el DPD, el DRAE

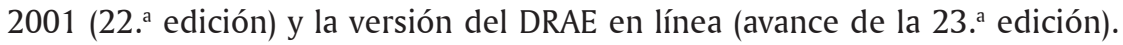
En el DRAE 2001, hobby se define de la siguiente manera: «Pasatiempo, entretenimiento que se practica habitualmente en los ratos de ocio», mientras que en el DRAE en línea se enmienda la definición anterior: «Actividad que, como afición o pasatiempo, se practica habitualmente en los ratos de ocio». ¿A cuál de las tres acepciones deberemos atender?

En segundo lugar, no puede desconocerse la frecuencia de uso de hobby, palabra que aparece en 1370000 casos en la web en español (22-07-09) y en 27500 casos (22-07-09) en páginas del Perú.

Finalmente, afición o pasatiempo no son «los equivalentes españoles» de hobby; pues estas palabras no podrían reemplazarse entre sí sin que se altere el sentido del enunciado, como sucede, por ejemplo, en los siguientes casos: 1) «Mi hobby es la colección de carteras»; 2) «Mario Vargas Llosa habla sobre su afición al western»; 3) «Los juegos de mesa clásicos son uno de los pasatiempos más populares de América».

\section{marketing}

En el DPD (p. 418) aparece la palabra márquetin de la que se dice lo siguiente: «Adaptación gráfica propuesta para la voz inglesa marketing, 'conjunto de estrategias empleadas para la comercialización de un producto y para estimular su demanda' [...]. Aunque, por su extensión, se admite el uso del anglicismo adaptado, se recomienda usar con preferencia la voz española mercadotecnia [...]. En muchos países americanos se emplea, con este sentido, la voz mercadeo». Además de las diferencias entre los términos, por lo menos entre los especialistas de la Administración, debo agregar que la palabra marketing figura en el DRAE desde la 21. a edición (1992) y que revisando las fuentes que ofrece internet es evidente el uso mayoritario del extranjerismo crudo: en la web en español, marketing aparece en 12400000 casos (22-07-09), y en 1670000 casos (22-07-09) en páginas del Perú; mientras que márquetin, incluso en toda la web, aparece sólo en 20800 casos (22-07-09), en la web en español aparece en 16500 casos (22-07-09) y en páginas del Perú tan solo figura en 104 casos (22-07-09). Es evidente -así como en magacín- que la palabra márquetin, adaptación gráfica propuesta para marketing, es dejada de lado mayoritariamente.

\section{Mouse}

En el DPD (p. 556) aparece la palabra ratón de la que se dice lo siguiente: «Calco semántico del término inglés mouse, que se usa, en informática, para 
designar el pequeño dispositivo mediante el cual se maneja el cursor de la pantalla de la computadora [...]. La existencia de este calco hace innecesario el uso en español del término inglés». Sin embargo, el uso indica lo contrario; pues no sólo acostumbramos a escribir mouse en vez de ratón, sino que en internet, al buscar ratón, se encuentran millones de casos en que esta palabra sólo se refiere al 'mamífero roedor' mas no al 'pequeño dispositivo...'. En cambio, para la palabra mouse con la acepción 'pequeño dispositivo...', se encuentran en la web en español 2760000 casos (22-07-09), y 157000 casos (22-07-09) en páginas del Perú.

No entiendo cuál es el reparo para incluir mouse en el DRAE, si en la 22. ${ }^{a}$ edición figura mousse: «Plato preparado con claras de huevo que dan consistencia esponjosa a los ingredientes dulces o salados que lo componen». Quizás se argumente que en la 23. ${ }^{a}$ edición en línea (revisada el 22-07-09), esta palabra aparece con la siguiente indicación: «artículo propuesto para ser suprimido», lo cual, de concretarse, sería un desatino: desde hace ocho años (2001), la palabra mousse fue admitida por el DRAE y no ha perdido vigencia; ¿por qué retirarla entonces del Diccionario? Figuran 499000 casos (22-07-09) en los que se usa mousse en la web en español, y 4370 casos (22-07-09) en páginas del Perú. ¿Acaso dejaremos de escribir y hablar del mousse o de preparar y comer mousse si la palabra no llegara a figurar en la 23. ${ }^{a}$ edición del DRAE? (Un dato más: debo señalar que la información que conseguí el 22-07-09 ya no figura en línea. Tuve la fortuna de rescatar el dato a tiempo, pues ahora [27-07-09] sólo se dice lo siguiente: «La palabra mousse no está en el Diccionario».)

Ante el uso evidentemente predominante de mouse ('pequeño dispositivo...'), correspondería señalar, más bien, que se pronuncia [máus] y no [mouse]. Finalmente, sólo queda agregar que en el diario El Comercio del 9 de diciembre del 2008 se halla el siguiente titular: «Hoy cumple 40 años el 'mouse' de la computadora».

\section{Shock}

En el DPD (p. 134) aparece la palabra choque, que -según se dice- «hace innecesario el uso del anglicismo shock [...] con el sentido de 'depresión súbita de las funciones vitales, producida generalmente por graves traumatismos o conmociones intensas'». A lo que se agrega: "Igualmente innecesario es el uso de la palabra inglesa con el significado de 'emoción o impresión fuerte' [...]. Para este sentido general, pueden usarse en español, además de choque, otros términos, como conmoción, impresión, sorpresa o impacto». Además de usar indistintamente las palabras significado y sentido, sin ser siquiera sinónimas contextualmente y confundiéndolas con acepción, en el DPD se pasa por alto que, por 
lo menos en el Perú, la palabra choque tiene un uso muy específico, disociado de los campos de la Medicina y de la Sicología, como tampoco se toma en cuenta que no puede usarse indistintamente conmoción, impresión, sorpresa o impacto en vez de choque. Veamos algunos ejemplos que demuestran lo dicho hasta aquí: 1) «Choque de dos trenes ligeros en San Francisco deja saldo de 47 personas heridas»; 2) «El estilista Carlos Cacho se encuentra en shock tras conocer la noticia de la muerte de su amigo y colega Marco Antonio»; 3) «La muerte de un bebé prematuro que nació hace dos semanas antes de que su madre muriera por gripe A en España causó conmoción»; 4) «San Martín dejó grata impresión en su gira por Ecuador»; 5) «Gran sorpresa causo el nacimiento de un becerro con dos cabezas en el caserío Silleropata»; 6) «Una de las consecuencias notables de la crisis política de Honduras, a causa del golpe de Estado, es el impacto en el comercio de los países de Centroamérica».

Tomando el ejemplo 2) veamos el cambio de significación al usar choque y shock: a) «El estilista Carlos Cacho tuvo un choque tras conocer la noticia de la muerte de su amigo y colega Marco Antonio»; b) «El estilista Carlos Cacho tuvo un shock tras conocer la noticia de la muerte de su amigo y colega Marco Antonio». En a) daremos por hecho de que se trata de un choque automovilístico; mientras que en b) entenderemos que se trata de una 'depresión súbita de las funciones vitales'.

En este caso, a pesar de que la palabra choque, con las acepciones citadas en el DPD, figura en el DRAE por lo menos desde la decimoctava edición (1956), es evidente que en el uso mayoritario se prefiere el anglicismo crudo shock para referirse a la 'depresión súbita de las funciones vitales'. Y si del respaldo de internet se trata (como se deja explícito en la presentación oficial del DPD que se registra en la web) diré que para shock se registran 2320000 casos (22-07-09) en la web en español y 87100 casos (22-07-09) en páginas del Perú.

\section{Show}

En el DPD (p. 600) se encuentra la palabra show de la que se dice lo siguiente: «Anglicismo innecesario, pues su equivalente español espectáculo está plenamente vigente en el uso, tanto con el sentido recto de 'función pública destinada a entretener' como en el figurado de 'acción que causa escándalo' [...]. En sentido recto, el anglicismo puede sustituirse también, según los contextos, por función, gala, número o exhibición». Al respecto, detallo algunos comentarios que considero imprescindibles.

1. La palabra show figura en el DRAE desde el año 2001 (22. ${ }^{\text {a }}$ edición), es decir, hace ocho años la Academia admitió el uso de esta palabra; sin embargo, el 2005, el DPD señala que se trata de un «anglicismo innecesario» y presenta 
sólo ejemplos de fuentes de España (de hace más de 10 años) para avalar el uso de espectáculo en vez de show. Y no sólo eso: todo parece indicar que la palabra show será definitivamente eliminada en la próxima edición del DRAE, pues en la versión en línea (avance de la 23. a edición), la palabra show ha desaparecido: «La palabra show no está en el Diccionario» (27-07-09). ¿Qué deberán hacer entonces quienes no tienen el DPD en casa? ¿Todos deberán recurrir al DPD en línea para enterarse de que lo que dice el DRAE 2001 no se admite en el DPD?

2. ¿La palabra «dejará de existir» porque no aparezca en la próxima edición del Diccionario? ¿Vamos a cerrar los ojos a las evidencias?: la palabra show aparece en la web en español en 60400000 casos (22-07-09), y en 808000 casos (22-07-09) en páginas del Perú; mientras que espectáculo aparece en 16900000 casos (22-07-09) en la web español, y en 299000 casos (22-07-09) en páginas del Perú. No niego lo evidente: es cierto que se usa espectáculo; pero, asimismo, qué duda cabe de que show le ha ganado mucho terreno. ¿Por qué no reconocer este hecho? ¿Se cree acaso que por el ingreso de algunos extranjerismos «el español se va a convertir en otra lengua»?

3. Por otra parte, es preocupante que en el DPD se mantenga la vieja y errónea diferenciación entre «sentido recto» y «sentido figurado». El DRAE 2001 superó esto y, con tino, eliminó la marca fig. ('figurado') de las definiciones. Al respecto, el semantista español Ramón Trujillo Carreño (2005) comenta lo siguiente: «¿Cómo se llegó a la conclusión de que la distinción entre lo de recto y lo de figurado no conduce a ninguna parte? ¿No sabían los autores del Diccionario que no existían en realidad significados rectos y figurados como "objetos" diferentes, o, mirado desde otro ángulo, que es siempre recta la forma de cada palabra, si se separa de sus usos o variantes, y que es siempre figurada cada variante particular, cada percepción individual de una palabra en una circunstancia cualquiera?». Obsérvese, además, que en el DPD se dice que el "sentido recto» de espectáculo es 'función pública destinada a entretener' y que, en ese mismo "sentido recto», el anglicismo show «puede sustituirse también, según los contextos, por función, gala, número o exhibición». En conclusión, ¿el «sentido recto» de espectáculo es el mismo "sentido recto» de show, función, gala, número y exhibición? Pues aunque el DPD nos diga que la sustitución se puede efectuar "según los contextos», queda claro que deja a nuestro libre albedrío la sustitución, la cual podrá efectuarse por lo menos con alguna de las acepciones de función, gala, número o exhibición, que de ninguna manera comparten el mismo "sentido recto» que el de espectáculo. Téngase en cuenta que en el DRAE 2001, recto se define en su 5. ${ }^{\text {a }}$ acepción así: «Se dice del sentido primitivo o literal de las palabras, a diferencia del traslaticio o figurado"; mientras que figurado, en su 2. acepción, se define de la siguiente manera: «Se dice del sentido en que se toman las palabras para que denoten idea diversa de la que recta y 
literalmente significan». ¿Cuál será, entonces, para el Diccionario, el «sentido recto» de recto y figurado, teniendo en cuenta que recto tiene 11 acepciones para su forma simple, y figurado, tres? ¿Es «recto» o «figurado» lo que se dice en la $5 .{ }^{\mathrm{a}}$ acepción de recto, y en la $2 .^{\mathrm{a}}$ acepción de figurado? ¿Cómo determina el DRAE el «sentido recto» o el "sentido figurado» de una palabra? Urge saber esto porque, volviendo nuevamente al DRAE 2001, función tiene 14 acepciones; gala, nueve; número, 14; exhibición, una ('acción y efecto de exhibir'). ¿Cuál de las acepciones de estas palabras hemos de elegir para que case con el «sentido recto» de espectáculo? (No se pierda de vista, además, que exhibición tiene por lo menos dos acepciones, no una: 'acción de exhibir', por un lado, y 'efecto de exhibir', por otro.)

4. Finalmente, presentaré algunos ejemplos para que los lectores saquen sus propias conclusiones acerca de si show, espectáculo, función, gala, número y exhibición son sustituibles entre sí: 1) «Los más de 60 actores fueron saliendo al escenario para sorprender a los asistentes, que acudieron masivamente a ver el primer show de esta compañía»; 2) «El espectáculo de motociclismo que se iba a realizar en Lima, Trujillo y Arequipa se canceló»; 3) «La primera función en el Perú (medianoche) en la más grande y mejor sala de Lima (Sala 9 del UVK Larcomar) la tenemos nosotros»; 3.1) «Artistas llegaron a función de gala del circo de la Chola Chabuca»; 4) «La cantante peruana Brenda Mau derrochó talento musical en su primera intervención en la gala final de Operación Triunfo»; 5) «Durante el comienzo de la ceremonia de los Oscar, el australiano Hugh Jackman deleitó al público con el tradicional número musical de entrada»; 6) «El pasado viernes 14 de diciembre del 2007, el Instituto Peruano de Taekwon-Do realizó con éxito dos exhibiciones de Taekwon-Do».

\section{Entradas o definiciones erróneas}

$E x$

En el DPD (p. 281) se encuentra la entrada ex, cuya definición, que no puede ser lexicográfica (por tratarse, en este caso, de una categoría gramatical), se presenta de la siguiente manera: «1. Prefijo autónomo de valor adjetivo, procedente de una preposición latina, que se antepone a sustantivos o adjetivos con referente de persona para significar que dicha persona ha dejado de ser lo que el sustantivo o el adjetivo denotan. Se escribe separado de la palabra a la que se refiere, a diferencia del resto de los prefijos, y sin guion intermedio: «Mi hijo no se fue solo, sino con su padre y mi ex suegra» [...]; «El ex alto cargo de Obras Públicas aseguró que con su misiva solo pretendía agilizar procedimientos administrativos» [...]». De esta manera, el DPD presenta el mismo desacierto que el DRAE 2001 en el que figura lo siguiente: 
ex. (De ex, prep. lat). adj. Que fue y ha dejado de serlo. Ex ministro, ex marido. $[\ldots]$

¿Cómo ha de entenderse la denominación de "prefijo autónomo", si un prefijo se caracteriza justamente por ser una partícula ligada? ¿A qué se debe el cambio de categoría gramatical? Hasta la 21. ${ }^{a}$ edición del Diccionario (DRAE 1992), ex se definía como preposición, lo cual era consecuente con la etimología que hace explícita el DRAE 2001. Veamos lo que se encuentra en el DRAE 1992:

ex. (Del lat. ex.) prep. que, antepuesta a nombres de dignidades o cargos, denota que los tuvo y ya no los tiene la persona de quien se habla; v. gr.: Ex provincial, ex ministro. || 2. También se antepone a otros nombres o adjetivos de persona para indicar que esta ha dejado de ser lo que aquellos significan: Ex discípulo, ex monárquico. [...]

Visto lo anterior debo decir que la categoría gramatical de ex no es adjetivo, pues en los ejemplos que presenta el DRAE 2001, ex no expresa cualidad o accidente, ya que si decimos que alguien es un honesto ciudadano, un respetable candidato, un excelente alumno o expresiones semejantes, entendemos a honesto, respetable, excelente como adjetivos, pero no sucede lo mismo si decimos que el ciudadano, el candidato o el alumno son ex. ¿Qué cualidad o accidente denota $e x$ en los ejemplos que presentan el DPD y el DRAE 2001? Una frase como ex suegra equivale a 'suegra que fue y ya no lo es', y toda esa información no es un adjetivo. Evidentemente, y ciñéndonos a la etimología hecha explícita en el Diccionario, ex funciona como preposición y no como adjetivo. No sé cuál sería el inconveniente para que en el DPD se efectuara la enmienda, sobre todo cuando en el caso de pro (p. 524) sí se hace un deslinde adecuado diciéndose lo siguiente: «1. Como sustantivo, 'provecho o ventaja'. [...] 2. Como preposición, se antepone a sustantivos sin determinante y significa 'en favor o en beneficio de': Fundación pro Real Academia Española [...]. Se escribe siempre separada del sustantivo al que acompaña. No debe confundirse con el prefijo pro- [...]». Salvo por la palabra "significa», estoy conforme -por su coherencia- con lo que se dice acerca de pro. Respecto de lo que significa una palabra, coincido con Ramón Trujillo Carreño (1996) en que toda palabra tiene un solo significado aunque pueda tener uno o varios referentes. Así, pro (o ex) no tiene tantos significados como acepciones presenta: el significado es siempre uno solo; es un error confundir significado con acepción. El significado de una palabra no cambia (para afirmar el cambio habrá que probarlo); las acepciones, en cambio, pueden ser muchas, e incluso pueden modificarse o desaparecen de acuerdo con el uso de los hablantes.

Volviendo a $e x$, el DPD presenta la misma palabra con otro uso: «2. También funciona como sustantivo denotando la persona que ha dejado de ser cónyuge 
o pareja sentimental de otra: «Mi ex y yo éramos dos enemigos sin ganas de pelear» [...]. Es invariable en plural: Todos mis ex se parecen». De esta manera, coincide con lo hallado en el DRAE 2001; sin embargo, no debe perderse de vista un detalle importante: el nivel de uso. En el Diccionario, se define como sustantivo común y queda sobreentendido que se trata de un uso formal y general, pues no presenta marca de nivel de uso linguiístico ni marca diatópica, cuando, por lo menos en el Perú, ex con función de sustantivo es de uso coloquial. ¿Debe admitirse, entonces, que en todo el territorio de habla hispana, ex, con función de sustantivo, corresponde al uso formal?

\section{Prerrequisito}

En el DPD (p. 571) se encuentra la palabra requisito que se define de la siguiente manera: “Condición necesaria para algo”. Y se agrega: «Esta palabra ya lleva implícita la idea de anterioridad; por tanto, la forma prerrequisito solo debe usarse si se refiere expresamente a un requisito previo a otro u otros requisitos; así, en Puerto Rico y otros países de América, se llama prerrequisito a la asignatura obligatoria y previa a otra que también lo es para alcanzar un grado». iQué redundancia tan flagrante! Si se reconoce que la palabra requisito "ya lleva implícita la idea de anterioridad», ¿por qué se admite la forma redundante *prerrequisito? Y el hecho se agrava porque se insiste en la contradicción al decir que la «forma prerrequisito solo debe usarse si se refiere expresamente a un requisito previo a otro u otros requisitos». ¿Es que hay algún requisito que no implique un hecho previo? Se recoge el mismo error en el que incurre el DRAE 2001, donde figuran entradas independientes para requisito y prerrequisito. En la 21. a edición del Diccionario (DRAE 1992) sólo figuraba la palabra requisito, 'circunstancia o condición necesaria para algo'; pero en la 22. a edición del DRAE aparece, además de requisito, la palabra prerrequisito con dos acepciones: la primera, 'requisito previo' (vuelvo a preguntar si hay algún requisito que no implique un hecho previo); la segunda (para Chile y P. Rico) coincide con lo que se encuentra en el DPD: 'asignatura obligatoria y previa a otra que también lo sea para alcanzar un grado'. Ante lo hallado en el DPD, ¿cómo vamos a corregir entonces a un alumno si escribe, por ejemplo, "antecedente previo; si la Academia avala el uso de la forma redundante prerrequisito, ¿qué impedirá que se escriba subir arriba, bajar abajo, entrar adentro...? Requisitos puede haber miles, pero no porque un requisito preceda como condición a otro deja de ser requisito para pasar a ser *prerrequisito. (Si se trata de redundar con el fin de «jerarquizar», que se invente, entonces, de acuerdo al orden, *prerrequisito, *pre-prerrequisito, *pre-pre-prerrequisito, y así sucesivamente.) Debemos ser consecuentes con la definición de requisito ('circunstancia o condición necesaria para algo’): *prerrequisito está de más. 


\section{Sigla y acrónimo}

En el DPD (p. 603) se encuentra la palabra sigla, que se define enciclopédicamente de la siguiente manera: «Se llama sigla tanto a la palabra formada por las iniciales de los términos que integran una denominación compleja, como a cada una de esas letras iniciales. [...] Hay siglas que se leen tal como se escriben, las cuales reciben también el nombre de acrónimos ( $\rightarrow$ ACRÓNIMO): ONU, OTAN, láser, ovni. [...] Hay siglas cuya forma impronunciable obliga a leerlas con deletreo: $F B I$ [éfe-bé-í], $D D T$ [dé-dé-té], $K G B$ [ká-jé-bé]. [...] Las siglas suelen omitir para su formación los artículos, las preposiciones y las conjunciones que aparecen en la denominación completa, salvo cuando se desea facilitar su pronunciación, convirtiéndolas en acrónimos [...]». Mientras que del acrónimo (p. 17) se dice lo siguiente: «Es, por un lado, el término formado por la unión de elementos de dos o más palabras: teleñeco, de televisión y muñeco; docudrama, de documental dramático; Mercosur, de Mercado Común del Sur. Por otro lado, también se llama acrónimo a la sigla que se pronuncia como una palabra: OTAN, ovni, sida $(\rightarrow$ SIGLA). [...] Los acrónimos suelen omitir para su formación los artículos, las preposiciones y las conjunciones que aparecen en la denominación completa, salvo si son necesarios para facilitar su pronunciación: ACUDE (por Asociación de Consumidores y Usuarios de España), pyme (por pequeña y mediana empresa). [...] Una vez incorporados al léxico común, los acrónimos forman el plural siguiendo las reglas generales de su formación en español [...]: ovnis, ucis, radares, transistores. [...]». Lo citado hasta aquí es inconsistente, además de confuso. Me explico, detalladamente, a continuación.

1. La sigla no es lo mismo que el acrónimo. Las siglas no se convierten en acrónimos cuando "se leen tal como se escriben», pues ambas formas de abreviación «se leen tal como se escriben», lo que no sucede, por ejemplo, con las abreviaturas (otro de los tipos de abreviación, además de los símbolos). Hace más de 10 años, Baldoceda (1995) hizo una muy lúcida distinción entre sigla y acrónimo; posteriormente, Ferrell (1998) insistió en el tema y mostró, además, ejemplos obtenidos de la prensa peruana, y en el III Congreso de Lexicología y Lexicografía realizado en el Perú (2008) volví a tratar el tema a propósito de cómo define el DRAE 2001 sigla y acrónimo. (Los tres catedráticos somos miembros de la Comisión de Ortografía y Lexicografía de la Academia Peruana de la Lengua desde el año 2000.)

2. En el DPD se confunde sigla con acrónimo, pues se ignora que estos tipos de abreviación responden a construcciones diferentes: la sigla se forma con la letra inicial de una palabra o con las letras iniciales consecutivas de las palabras que constituyen la construcción compleja a la que se alude, como es el caso de ovni (de objeto volador no identificado) o de sida (de síndrome de 
inmunodeficiencia $a$ dquirida, de lo que se ha derivado una sigla impropia, pues la $d$ no es inicial de palabra); mientras que el acrónimo (según el DRAE 2001: "Del gr. ö́kpos, extremo, y -ónimo») se forma con las sílabas iniciales y finales de las palabras (por lo menos dos) a las cuales se alude, como en el caso de teleñeco (de televisión y muñeco) o de transistor (de transfer y resistor). Asimismo, para formar una sigla sólo puede tomarse como máximo una sílaba de cada una de las palabras que constituyen la construcción compleja a la que se alude; mientras que para formar un acrónimo sí se puede tomar más de una sílaba (mientras no se tome una palabra completa, lo cual tampoco puede hacerse en el caso de la sigla) de las palabras a las cuales se alude.

3. La sigla se puede leer por silabeo: ONU, OTAN, láser, ovni, o por deletreo: $F B I, D D T, K G B$ (no son «impronunciables»), según lo determine la estructura silábica del conjunto grafémico resultante. En cambio, los acrónimos nunca se deletrean: teleñeco, transistor, teletón, informática, ofimática.

4. El DPD presenta siglas impropias sin señalar que lo son, y, con ello, además de persistir en la confusión entre sigla y acrónimo, induce al error en la formación de estos tipos de abreviación. Son siglas impropias, por ejemplo, MERCOSUR (de Mercado Común del Sur) y pyme (por pequeña y mediana empresa), pues incluyen no sólo letras o sílabas iniciales de la construcción compleja sino una palabra completa, ya sea sustantivo, conjunción, preposición o adverbio: MERCOSUR incluye un sustantivo completo (sur), y pyme una conjunción completa $(y)$. (Por tanto, MERCOSUR no es una sigla sino una palabra formada mediante un procedimiento mixto de sigla $[M E R$ y $C O]$ y composición: el sustantivo completo SUR se suma a las dos abreviaciones precedentes, MER y CO.) En el caso de ACUDE (por Asociación de Consumidores y Usuarios de España) no puede decirse que se trata de una sigla impropia, pues su formación se explica a partir de la unión de las siguientes letras iniciales: A (Asociación), C (Consumidores), U (Usuarios), D (de), E (España). Teniendo en cuenta lo mencionado hasta aquí, no es correcto decir que se agrega una palabra completa "para facilitar la pronunciación»; pues si se toma una palabra completa ya no estaremos ni ante una sigla ni ante un acrónimo, como ya se vio en el caso de MERCOSUR. Para terminar este acápite, completaré una idea planteada antes: la sigla sida está mal formada porque en inmunodeficiencia, sólo la letra o sílaba inicial del prefijo (inmuno-) debió representar a la palabra.

5. Vemos, entonces, que definir acrónimo como «el término formado por la unión de elementos de dos o más palabras» implica incurrir en una imprecisión muy grave, pues esta definición podría involucrar no sólo al acrónimo y a la sigla, sino también a procedimientos como la composición y la parasíntesis, por ejemplo. 


\section{Entradas y definiciones en las que predomina injustificadamen- te el género masculino}

\section{Jefe}

En el DPD (p. 380) se encuentra la palabra jefe, que se define de la siguiente manera: «Persona que manda sobre otras'. Por su terminación, es común en cuanto al género (el/la jefe [...]): «Campos fue en aquella ocasión la jefe de expedición» [...]; pero cuando el jefe es una mujer ha sido siempre más frecuente el uso del femenino específico jefa, registrado en el diccionario académico desde 1837: «Habían decidido promoverla a jefa de un área que no existía hasta entonces» [...]. Si el referente es una mujer, puede usarse indistintamente la forma común jefe o el femenino específico jefa: redactora jefe o redactora jefa [...]». Sin embargo, a pesar de lo reconocido explícitamente en el DPD, no se consigna en una sola entrada jefe, $f a$, sino se presenta una entrada específica para jefa, que remite a jefe. Así, el DPD arrastra la misma inconsistencia del DRAE 2001 donde figura lo siguiente:

jefe. (Del fr. chef). com. Superior o cabeza de una corporación, partido u oficio. || 2. Mil. Militar con cualquiera de los grados de comandante, teniente coronel y coronel en el Ejército, o los de capitán de corbeta, capitán de fragata y capitán de navío en la Armada. [...]

jefa. (De jefe). f. Superiora o cabeza de un cuerpo u oficio. || 2. coloq. p. us. Mujer del jefe.

No piense algún optimista que la presencia de dos entradas favorece en algo a la variante femenina jefa; pues, más bien, la margina: todo lo que se dice en jefa depende de jefe, desde la información etimológica. Detallo a continuación algo más al respecto:

1. La entrada jefa depende de jefe porque la primera acepción de jefa contiene sólo una parte de la primera acepción de jefe. Dejando de lado el tema de la presencia de contorno (elemento o elementos ajenos a la definición propiamente dicha) en ambas definiciones, el jefe-según está definido- es 'superior o cabeza de una corporación, partido u oficio'; en cambio, la jefa sólo es -según el DRAE- 'superiora o cabeza de un cuerpo u oficio': nada tiene que ver con una corporación o con un partido. Asimismo, en la 2. a acepción de jefa, que lleva la marca de poco usado (p. us.), se lee 'mujer del jefe', lo que implica recurrir necesariamente a la entrada jefe.

2. Vistas las dos acepciones admitidas para jefa, todo lo demás tendremos que buscarlo en jefe, que en el caso de su segunda acepción que lleva la marca técnica Mil. ('milicia') sólo podrá aplicarse como común, por lo que -siguiendo al DRAE- se dirá la jefe, no la jefa. (A propósito de la marca técnica, esta es innecesaria, no sólo porque se trata de una palabra de uso general, sino también 
porque la definición ya comienza con el hiperónimo militar.) ¿A qué vamos a atenernos si -de acuerdo con lo citado anteriormente- en el DPD se dice: «Si el referente es una mujer, puede usarse indistintamente la forma común jefe o el femenino específico jefa»? Mientras que en el DPD se nos da esta información (aunque sin consignar en una sola entrada jefe, $f a$ ), en el avance de la 23. a edición del DRAE en línea, la situación sigue siendo la misma que en el DRAE 2001 (22. ${ }^{\text {a }}$ edición): ¿es que tampoco importan los 3640000 casos (21-07-09) de uso de la palabra jefa que figuran en la web?

3. ¿Cuál es la razón para definir las entradas por separado, si no es destacar la primacía de una forma sobre otra? ¿Por qué persistir en separar las entradas a pesar de lo dicho en el DPD y siendo, además, antieconómico? Por todo lo expuesto, hago la siguiente propuesta para la primera acepción (Portilla, 2008):

jefe, fa. (Del fr. chef.) m. y f. Referido a una entidad o partido político: Superior o cabeza. [...]

\section{Presidente}

En el DPD (p. 520), la palabra presidenta remite a presidente, que se define de la siguiente manera: «Persona que preside algo' y, en una república, 'jefe del Estado'. Por su terminación, puede funcionar como común en cuanto al género (el/la presidente [...]): «La designación de la presidente interina logró aplacar la tensión» [...]; pero el uso mayoritario ha consolidado el femenino específico presidenta: «Tatiana, la presidenta del Comité, no le dejaba el menor espacio» [...]». $\mathrm{Al}$ respecto, presento a continuación algunos comentarios.

1. Obsérvese que a diferencia de la palabra jefe, respecto de la que se decía: «Por su terminación, es común en cuanto al género», en el caso de presidente se dice "puede funcionar como común en cuanto al género» (el subrayado es mío); es decir, presidente no «es común», sino que "puede funcionar como común».

2. El tema del género de los sustantivos debe ser abordado con un criterio democrático y unificador no sólo por el DPD sino también por el DRAE. Sin ser feminista, entiendo que quienes forman parte de ese grupo se quejen ante las muestras de parcialidad de ambas fuentes de consulta, ya que el DPD así como el DRAE inclinan siempre la balanza a fin de destacar el género masculino aunque la difusión de uso señale lo contrario, con lo que el sectarismo se refuerza. Si no es así, ¿cómo se explica el hecho de que ante lo explícitamente reconocido por el DPD, no se presente en una única entrada presidente, ta? La postura ambivalente del DPD, mucho más notoria en el caso de presidente que en jefe, avala el desdoblamiento injustificado de las entradas presidente y presidenta, al igual que en el DRAE 2001: 
presidente. (Del ant. part. act. de presidir; lat. praeš̀dens, -entis). adj. Que preside. || 2. com. Persona que preside. || 3. Cabeza o superior de un gobierno, consejo, tribunal, junta, sociedad, etc. $\| 4$. En los regímenes republicanos, jefe del Estado normalmente elegido por un plazo fijo. [...]

presidenta. f. Mujer que preside. || 2. presidente (|cabeza de un gobierno, consejo, tribunal, junta, sociedad, etc.). || 3. presidente (||jefa del Estado). \| 4. coloq. Mujer del presidente.

Nótese que -según el DRAE- todo lo que puede ser una presidenta está siempre supeditado a presidente: las acepciones de las formas en femenino no van en ningún caso más allá del masculino, como ya se vio en jefa. La entrada presidente presenta incluso una acepción en específico para el uso adjetivo, que no figura en el caso de presidenta; mejor dicho, qué duda cabe de que la forma adjetiva presidenta existe en la lengua hablada así como en la lengua escrita, pero eso no cuenta para el Diccionario, que sustenta el predominio de presidente en la terminación de la palabra $(-e)$ antes que aceptar democráticamente el uso de las mayorías. (Aunque este argumento parece ser sólo un pretexto porque, por ejemplo, en el caso de ingeniero, ra y abogado, da, el predominio del masculino persiste a pesar de considerar las variantes de género en una misma entrada [Portilla, 2008].) Es de lamentar, por ello, que el DPD no haya tomado una postura acorde con el devenir linguístico del español y que, por lo que se ve en el avance de la 23. a edición del DRAE, la situación, al respecto, siga siendo la misma que desde hace varias décadas.

\section{Conclusiones}

Por su nombre, un diccionario de dudas debe ser aquella fuente de consulta que permita resolver interrogantes, por ello, preocupan seriamente las inconsistencias, contradicciones y ambivalencias halladas en la presente revisión del DPD.

A través de la investigación expuesta -como dije al principio- no se agota el análisis del DPD ni tampoco se dan las soluciones definitivas a los puntos tratados; pero sí se discute y se pone en alerta acerca de algunos aspectos relacionados con la lengua en uso, los cuales deberían ser reconsiderados en una próxima edición del DPD.

1) Cuando trato acerca de los usos CONSIDERADOS «INNECESARIOS» no pretendo que prevalezcan los extranjerismos sobre las voces propias del español, lo que busco es mostrar lo evidente: hay algunas voces extranjeras que se usan más que sus equivalentes en español, o que simplemente no admiten equivalencia, y eso no tiene por qué negarse ni ocultarse como si se tratara de una especie de "pecado capital», pues no por este hecho el español va a «convertirse», por 
ejemplo, en inglés o en francés. Mientras que los usuarios consideren que una palabra extranjera es más favorable para su intercomunicación, seguirán usando dicha palabra. Así, decía Lázaro Carreter (2002) que «es casi seguro que una clínica se quedaría sin clientela si en lugar de anunciar liftings ofreciera estiramientos de piel. Por tanto, lifting es palabra precisa». Y esto es así aunque en el DPD (p. 398) se recomiende "sustituirlo por el equivalente español estiramiento (facial)», y así seguirá siendo -como dije líneas antes- si los usuarios siguen considerando que lifting es más útil (o utilitario) que "estiramiento (facial)». 2) En el caso de las ENTRADAS o DEFINICIONES ERRÓNEAS corresponde que en el DPD se replantee lo dicho y se eliminen las inconsistencias y contradicciones, pues éstas sólo generan más interrogantes. 3) Respecto de las ENTRADAS Y DEFINICIONES EN LAS QUE PREDOMINA INJUSTIFICADAMENTE EL GÉNERO MASCULINO, en el DPD se debe atender -y lo mismo en el DRAE- a lo gramaticalmente posible en vez de insistir en la primacía de una regla contraria a lo que la lengua española genera naturalmente; así se evitará que al DPD también se le acuse de "sexista y machista», como las feministas han calificado al DRAE 2001 (Grupo La República, 2002).

Ciertamente, toda obra es perfectible. En la Academia Peruana de la Lengua habemos profesionales dispuestos a sumar esfuerzos en pro de una Ortografía, una Gramática y un Diccionario más solventes, a partir de los cuales el DPD podría constituirse en una especie de puente entre lo que es la norma establecida y su variación diatópica, diafásica y diastrática. Así, el DPD no sólo daría testimonio de dicha variación sino también propondría a tiempo la adecuación más recomendable, no sólo según el patrón linguiístico del español, sino también de acuerdo al uso realmente panhispánico.

Termino este artículo citando las palabras de Fernando Lázaro Carreter (2002), palabras que él compartió con quienes formamos la primera promoción de la Escuela de Lexicografía de la Real Academia Española a propósito de la presencia de neologismos en el DRAE 2001: «Evidentemente, si se quisiera acentuar el carácter rígidamente normativo, lo convertiríamos en un catálogo de antiguiedades $[\ldots]$. Dejaríamos fuera del lenguaje a los millones de hablantes que van al cine, a la discoteca, al fútbol, que se expresan en los periódicos, ante los micrófonos o las cámaras, y hablan en juzgados, en cámaras legislativas, en aulas o, incluso, en las sesiones académicas». Tratemos, pues, que el Panhispánico haga honor a su nombre.

\section{Referencias bibliográficas}

BALDOCEDA E., Ana M. (1995). «Abreviaciones en la lengua escrita». Alma Máter 10; pp. 99-113.

FERRELL R., Marco Aurelio (1998). Manual de uso idiomático, Lima, 2. ${ }^{\text {a edición. }}$ 
LUISA Portilla DuRand

GRUPO LA REPÚBLICA (2004). «Acusan de sexista y machista al diccionario de la Lengua». Fama, suplemento cultural de La República, Lima, 16-11-04; p. 7.

LÁZARO CARRETER, Fernando (2002). «El neologismo en el diccionario». Accesible en http://sites.google.com/site/publicacionesvarias, julio del 2009.

PORTILLA DURAND, Luisa P. (2008). «El DRAE, una tarea que no acaba sino para empezarla de nuevo». Actas del III Congreso Internacional de Lexicología y Lexicografía «Diego de Villegas y Quevedo Saavedra», Lima, APL-UPSMP; pp. 559-580.

REAL ACADEMIA ESPAÑOLA (1956). Diccionario de lengua española. Madrid, Espasa Calpe S.A.

REAL ACADEMIA ESPAÑOLA (1992). Diccionario de lengua española. Madrid, Espasa Calpe S. A.

REAL ACADEMIA ESPAÑOLA (2001). Diccionario de lengua española. Madrid, Espasa Calpe S. A.

REAL ACADEMIA ESPAÑOLA (2009). Diccionario de lengua española (avance de la 23. ${ }^{\text {a }}$ edición). Accesible en http://buscon.rae.es/drael, julio del 2009.

REAL ACADEMIA ESPAÑOLA Y ASOCIACIÓN DE ACADEMIAS DE LA LENGUA ESPAÑOLA (2005). Diccionario panhispánico de dudas. Bogotá, Santillana.

TRUJILLO CARREÑO, Ramón (1996). Principios de semántica textual/Los fundamentos semánticos del análisis lingüístico, Madrid, Arco/Libros.

TRUJILLO CARREÑO, Ramón (2005). «El concepto de "sentido figurado" en el DRAE y cuestiones afines». Homenaje al profesor Alvar López, Institución Fernando el Católico, Excma. Diputación de Zaragoza; pp. 735-753. 